\title{
PERSPEKTIF PHYLOGENESIS DAN ONTOGENESIS DALAM PENGEMBANGAN PEMBELAJARAN MATEMATIKA MENGGUNAKAN ASPEK SEJARAH MATEMATIKA
}

\author{
Shofan Fiangga ${ }^{\text {1) }}$, Abdul Haris Rosyidi ${ }^{2)}$, Tatag Yuli Eko Siswono ${ }^{3)}$ \\ 1),2),3) Universitas Negeri Surabaya \\ E-mail: shofanfiangga@unesa.ac.id ${ }^{1)}$ abdulharis@unesa.ac.id ${ }^{2)}$ \\ tatagsiswono@unesa.ac.i3 ${ }^{2)}$
}

\begin{abstract}
History of mathematics discusses a historical aspect of mathematics concepts since its appearance and development through ages. Understanding the background of why a certain concept appears in mathematics, an innovation in teaching and learning material may be developed. The historical aspect of mathematics concept can be used as guided reinvention activities for the children to learn the concept. This idea is in line with what stated in curriculum 2013. However, to implement in curriculum 2013, there is no feasible framework that can be used to work on. One perspective that can be used in this implementation is phylogenensis and ontogenesis perspective. In this paper a discussion on how phylogenesis and ontogenesis may be used to implement the history in teaching mathematics will be presented. In addition, an example on how a history can be used as reference in learning is provided.
\end{abstract}

Keywords: History of mathematics, Ontogenesis, Phylogenesis.

\section{PENDAHULUAN}

Diskusi mengenai pentingnya implementasi sejarah pada pembelajaran matematika telah lama diperbincangkan. Sebagian studi membahas mengenai alternatif penggunaan aspek sejarah pada pembelajaran matematika (Katz, 1993; Michalowicz, Daniel, FitzSimons, Ponza, \& Troy, 2002; Ozdemir, Goktepe, \& Kepceoglu, 2012; Tzanakis et al., 2000). Sedangkan sebagian yang lain membahas mengenai bagaimana mengukur kefektifan suatu pembelajaran yang mengimplementasikan sejarah sejarah (Barbin et al., 2002; Panasuk \& Bolinger Horton, 2013; Radford et al., 2002). Banyak yang mendukung ide mengenai perlunya aspek sejarah matematika diintegrasikan pada pembelajaran matematika di kelas. Namun, tidak sedikit yang menentang ide tersebut. Dari diskusi tersebut, dapat disimpulkan bahwa ada lima area pembelajaran matematika yang dapat diperkuat melalui integrasi sejarah matematika ini. Proses pembelajaran tersebut adalah: (1) konsep matematika dipelajari, (2) pengembangan sudut pandang mengenai ilmu matematika dan kegiatan matematis, (3) latar belakang pengajaran dari guru dan kemampuan mengajarnya, (4) afeksi terhadap matematika, dan (5) apresiasi matematika sebagai aktivitas manusia (Tzanakis et al., 2000).

Seperti yang sudah dibahas sebelumnya, matematika merupakan hasil dari proses evolusi intelektual manusia secara terus menerus yang terikat kuat dengan ilmu pengetahuan lain, keadaan sosial dan budaya pada jamannya dimana matematika sebagai aktivitas manusia itu sendiri (Gravemeijer, 2013). Apresiasi 
matematika sebagai aktivitas manusia dapat disajikan dalam berbagai bentuk. Di antaranya adalah bagaimana konsep matematiika tersebut berkembang untuk menyelesaikan suatu permasalahan, apa motivasi apa yang ada di masanya, aspek estetika, keingintahuan, tantangan dan fungsi rekreasi yang bagaimana yang bisa diambil dari sejarahnya. Hal lain yang bisa didiskuiskan pada sejarah matematika suatu konsep adalah bagaimana suatu konsep yang sama berkembang di beberapa tempat berbeda sekaligus. Salah satu teori yang memperkuat penerapan sejarah pada pembelajaran adalah perspektif hubungan antara ontogenesis dan phylogenesis (Radford, 1997, 2015). Ontogenesis merupakan bagaiman intelektual dari suatu individu berkembang mengikuti perjalanan usianya. Bayi tentu belum bisa memahami apa yang dimaksud dengan bilangan real, mereka baru bisa memahami tentang ada atau tidak ada sebagaimana 1 dan 0 saling menggantikan. Sedangkan phylogenesis merupakan bagaimana intelektual manusia berkembang sejak jaman prasejarah hingga saat ini. Hal ini menjelaskan bagaiman manusia prasejarah sudah mampu memiliki kemampuan berhitung namun masih dalam semesta yang sederhana. Dua perspektif inilah yang dilihat mengalami perkembangan yang berjalan beriringan.

Pentingnya mahasiswa calon guru dalam mengetahui sejarah matematika tidak dapat dipungkiri lagi. Dengan mengetahui bagaimana suatu konsep matematika berkembang pada sejarahnya, pembelajaran matematika dapat dikembangkan menjadi lebih inovatif dan kreatif melalui kegiatankegiatan penemuan kembali konsepkonsep matematika tersebut. Beberapa contoh implementasi penerapan sejarah pada pembelajaran seperti penggunaan sejarah sebagai sumber motivasi, (2) penggunaan sejarah sebagai sumber kegiatan penemuan konsep, dan (3) penggunaan sejarah sebagai suatu permainan yang berhubungan dengan materi pembelajaran (Jankvist, 2009). Akan tetapi, tantangan terbesar dalam implementasi sejarah pada pembelajaran adalah bagaimana mengadaptasi suatu sejarah konsep matematika menjadi kegiatan pembelajaran yang relevan. Pada dasarnya, sejarah matematika dapat muncul dalam suatu pembelajaran dalam berbagai bentuk (Tzanakis et al., 2002). Beberapa contohnya adalah historical snippet, kegiatan penemuan berbasis proyek berdasarkan ilustrasi sejarah, Sumber belajar utama, Lembar kerja siswa, Permasalahan yang muncul pada sejarah matematika, Role play, Ilustrasi Audio Visual, Instrumen-instrumen matematis, dan lain lain. Berbagai bentuk pengembangan implementasi sejarah pada pembelajaran matematika dapat dijadikan referensi bagi mahasiswa calon guru dalam mengembangkan suatu pembelajaran matematika yang kreatif dan menyenangkan. Dengan adanya kurikulum 2013 yang menuntut siswa secara aktif dapat menemukan kembali konsep matematika, penerapan aspek sejarah pada pembelajaran bisa menjadi pendekatan yang menjanjikan.

Perkuliahn sejarah matematika yang sudah berlangsung di jurusan matematika sendiri masih menitik beratkan pada pembahasan informasi sejarah yang sangat banyak. Perkuliahan berjalan seperti memaksa semua materi matematika yang berkembang selama 3000 tahun untuk dibahas hanya dalam 2 SKS. Ditambah 
lagi tenaga pengajar yang belum memahami secara keseluruhan aspek sejarah dari suatu materi membuat kegiatan perkuliahan lebih didominasi kegiatan presentasi mahasiswa tanpa umpan balik yang maksimal dari pengajar. Hal inilah yang membuat mahasiswa mengeluhkan bahwa perkuliahan sejarah matematika cenderung tidak menghasilkan inovasi baru bagi mahasiswa dalam mengembangkan $\mathrm{p}$ embelajaran.

Implementasi perspektif hubungan antara ontogenesis dan phylogenesis diharapkan mampu memberi ide bagi mahasiswa mengenai bagaimana memanfaatkan suatu aspek sejarah dari konsep matematika. Mahasiswa bisa mengembangkan aspek sejarah dari suatu konsep matematika menjadi motivasi, kegiatan penemuan kembali, ataupun permainan yang dapat menarik minat siswa dalam belajar matematika. Selain itu, pada perkuliahan ini, akan disajikan beberapa contoh implementasi sejarah matematika dalam pembelajaran yang sudah siap. Sehingga mahasiswa memiliki referensi mengenai bagaimana suatu aspek sejarah dari suatu konsep dapat dikembangakn menjadi kegiatan pembelajaran yang menarik.

\section{PEMBAHASAN}

Kurikulum 2013 pada pembelajaran matematika mencoba mengubah pembelajaran yang cenderung mekanisitk menjadi pembelajaran yang bermakna melalui pendekatan saintifik (depdiknas). Dengan mengetahui sejarah dari suatu materi, dapat didesain pembelajaran dengan menemukan kembali konsep matematika dengan dibimbing oleh guru.

Dari hasil kajian literature, maka untuk mengimplementasikan aspek sejarah dari suatu materi pada pembelajaran matematika di kurikulum 2013 memiliki karakteristik umum dan bentuk implementasi sebagai berikut.

\section{Karakteristik Umum Integrasi Sejarah Matematika pada Pembelajaran Matematika}

Integrasi sejarah matematika pada pembelajaran sendiri dapat dikategorikan menjadi tiga bagian, yaitu: (1) belajar sejarah matematika, (2) belajar materi matematika yang diikuti pendekatan yang dikembangkan dari sejarahnya, dan (3) pemahaman akan matematika yang lebih dalam atas aspek sejarah matematika. Informasi sejarah secara langsung dapat disajikan sebagai potongan-potongan informasi mengenai sejarah matematika ataupun suatu pembelajaran lengkap dalam bentuk kuliah. Hal ini bisa dilihat pada potongan-potongan sejarah yang coba disajikan pada buku matematika tingkap SMP hingga SMA. Bagian selanjutnya membutuhkan kreatifitas guru dalam mendisain pembelajaran yang menarik dengan memanfaatkan aspek sejarah dari suatu materi. Guru dapat mendisain pembelajaran dengan merekosntruksi bagaimana matematikawan menemukan suatu konsep matematika, seperti konsep kesebangunan yang digunakan Thales untuk mengukur tinggi piramida. Pemahaman mengenai matematika sendiri sering dianggap sebagai suatu ilmu yang terpisah dari dunia nyata. Padahal, kenyataannya, berbagai perkembangan matematika sendiri secara tidak langsung terlibat dalam evolusi perkembangan manusia itu sendiri.

Bentuk-bentuk implementasi sejarah pada pembelajaran sendiri dapat dibagi menjadi tiga bagian, yaitu: (1) sumber sejarah primer, dimana dalam pembelajaran menggunakan sumber asli sejarah matematika berupa manuscript 
kuno, alat-alat perhitungan kuno dan lainnya, (2) sumber sejarah sekunder, dimana pembelajaran menggunakan referensi buku yang membahas mengenai sejarah matematika, dan (3) sumber kegiatan belajar, dimana pembelajaran menggunakan suatu pendekatan yang sudah dikembangkan dari sumber-sumber sejarah sebelumnya. Bagaiman sekma implementasi material tersebut dapat dilihat pada diagram berikut ini.

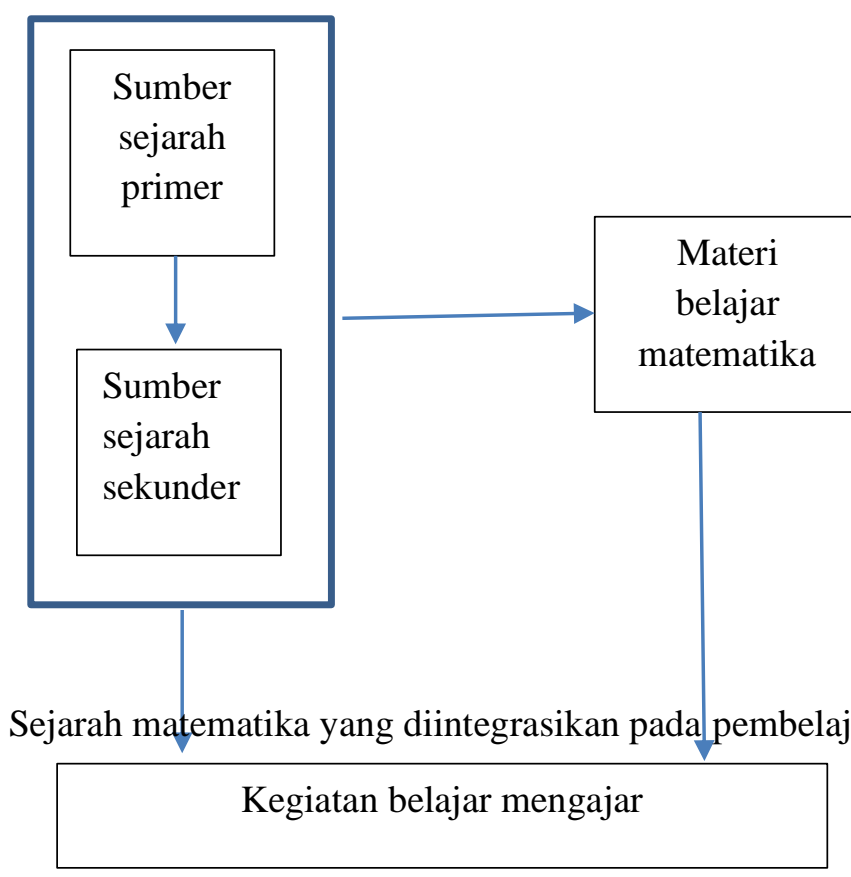

Gambar 1.diagram impelemntasi sejarah pada pembelajaran matematika (diadaptasi dari (Tzanakis et al., 2000))

Dari bagan pada Gambar 1, dapat kita lihat bahwa sumber sejarah primer dan sekunder dapat langsung digunakan dalama pembelajaran. Suatu sumber sejarah primer, kadangkala, cukup sulit untuk dipahami langsung, oleh karena itu, material sumber sekunder diperlukan untuk membandingkan interpretasi para ahli terhadap perkembangan sejarah tersebut. Akan tetapi, penggunaan sumber sejarah primer dan sekunder yang terlalu mentah kadang akan membuat siswa menjadi kesulitan dalam memahaminya. Selain itu, dari sumber sejarah primer dan sekunder, guru dapat mengembangkan sendiri materi pembelajaran yang diinspirasi dari sejarah suatu konsep matematika.
Sumber belajar inilah yang dapat membantu siswa lebih mudah dalam memahami suatu konsep, karena dalam mengembangkan sumber belajar yang dikembangkan dari sejarah matematikanya, guru perlu mempertimbangkan berbagai pendekatan dan sudut pandang agar memudahkan siswa.

\section{Bentuk Implementasi Sejarah Matematika pada Pembelajaran Matematika}

Objek sejarah matematika dapat muncul dalam suatu pembelajaran dalam berbagai bentuk (Tzanakis et al., 2002). Beberapa contohnya adalah sebagai berikut:

\section{Historical snippet,}


Berbagai implementasi sejarah matematika yang muncul pada buku teks pelajaran matematika dinamakan historical snippet. Dalam buku text, aspek sejarah ini bias muncul dalam berbagai bentuk mulai dari motivasi di awal bab pembelajaran, kegiatan penemuan di dalam bab pelajaran, dan juga bias menjadi tantangan atau permainan di akhir bab pelajaran.

\section{Kegiatan penemuan berbasis proyek berdasarkan ilustrasi sejarah,}

Beberapa phenomena sejarah dapat diangkat menjadi suatu kegiatan pembelajaran berbasis proyek. Contoh sederhananya adalah bagaimana Thales melakukan perhitungan untuk menghitung tinggi dari pyramida. Hal ini bias diadaptasi dalam konteks saat ini. Objek pyramid bias diganti dengan, misalkan, tiang bendera atau tugu pahlawan yang menjadi objek landmark kota Surabaya.

3. Sumber belajar utama,

Beberapa dokumen sejarah bisa menjadi sumber belajar yang lebih mudah bagi siswa. Contohnya pada proses menentukan akar kuadrat dari suatu bilangan. Pekerjaan yang dihasilkan pada jaman india arab bias membantu siswa untuk lebih memahami metode penemuannya dibanding hanya melakukan operasi-operasi tak bermakna.

\section{Lembar kerja siswa,}

Kegiatan pembelajaran di kelas bisa dikembangkan berdasarkan suatu fakta sejarah. Logaritma bisa dikenalkan dengan menggunakan aspek sejarah dari konsep tersebut.

5. Permasalahan yang muncul pada sejarah matematika,

Berbagai permasalahan yang muncul dalam perkembangan sejarah matematika dapata diangkat di kelas.
Beberapa kasus bisa didiskusikan menggunakan problem based learning.

6. Role play,

Untuk memahami bagaimana suatu konsep matematika berkembang bisa dilakukan suatu bentuk drama. Dalam drama ini, siswa bisa berperan menjadi pemecah permasalahan yang muncul di kala itu

7. Instrumen-instrumen matematis, Berbagai instrumen yang dikembangkan pada jaman dahulu secara matematis dapat dipelajari hingga saat ini. Sehingga, siswa dapat memahami konsep yang membentuk instrument-instrumen tersebut.

\section{Contoh Implementasi pada Pembelajaran Matematika (Thales dan Tinggi Piramida)}

Konsep kesebangunan sendiri sudah dipakai sejak Thales mencoba mengukur tinggi piramida di Mesir. Thales memanfaatkan bayangan yang dihasilkan dari matahari. Dari sini, Thales menyadari bahwa bayangan dari semua objek benda berubah mengikuti posisi matahari. Hal ini berlaku untuk semua objek.

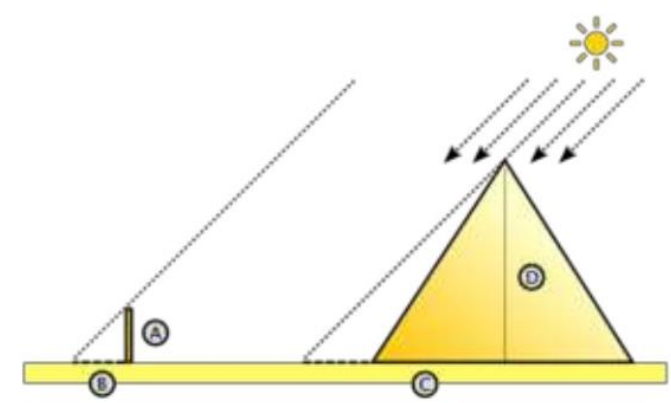

Gambar 2. Ilustrasi Thales dalam menghitung tinggi piramida

(Sumber gambar: Wikipedia)

Materi yang berhubungan dengan potongan sejarah ini adalah kesebangunan di kelas 9 SMP. Pada pembelajarannya, guru bisa mendisain suatu proyek dengan menggunakan metode bayangan Thales ini sebagai 
penyelesaiannya. Untuk objek yang diukur bisa diubah karena tidak mungkin kita mengukur piramida. Kita bisa membuat proyek pengukuran tinggi tiang bendera yang ada di sekolah atau proyek menghitung tinggi tugu pahlawan jika memungkinkan. Melalui kegiatan proyek seperti ini, konsep kesebangunan tidak hanya diajarkan secara formal saja namun juga kegunaan dalam konteksnya juga akan mampu dipahami siswa.

\section{KESIMPULAN DAN SARAN}

Sudut pandang Ontogenesis dan Phylogenesis memberikan alternatif penyajian sejarah dari suatu konsep matematika sehingga dapat diterapkan pada pembelajaran matematika sesuai dengan perkembangannya. Menggunakan perspektif Ontogenesis dan Phylogenesis dapat dikembangkan pembelajaran menemukan kembali konsep matematika tersebut dengan mengadaptasi perkembangan konsep tersebut di masa lalu. Perkembangan konsep matematika sesuai urutan waktu bisa disejajarkan dengan materi matematika yang diajarkan sejak tingkat dasar, tingkat menengah, hingga pendidikan tinggi.

Untuk dapat mengembangkan pembelajaran matematika yang menggunakan aspek sejarah, perlu dikembangkan disain penemuan kembali konsep matematika tersebut berdasarkan latar belakang sejarahnya. Sehingga, perlu dikembangkan panduan yang dapat digunakan sebagai referensi dalam mendisain pembelajaran menggunakan aspek sejarah.

\section{DAFTAR PUSTAKA}

Barbin, E., Bagni, G. T., Grugnetti, L., Kronfellner, M., Lakoma, E., \& Menghini, M. (2002). Integrating history: research perspectives (pp. 63-90). http://doi.org/10.1007/0-30647220-1_3

Gravemeijer, K. (2013). Revisiting “ Mathematics education revisited . Freudental 100, 24, 106-113. Jankvist, U. T. (2009). A categorization of the "whys" and "hows" of using history in mathematics education. Educational Studies in Mathematics, 71(3), 235-261. http://doi.org/10.1007/s10649008-9174-9

Katz, V. J. (1993). Using the history of calculus to teach calculus. Science and Education, 2(3), 243-249. http://doi.org/10.1007/BF004900 66

Michalowicz, K. D., Daniel, C., FitzSimons, G., Ponza, M. V., \& Troy, W. (2002). History in support of diverse educational requirements - opportunities for change (pp. 171-200). http://doi.org/10.1007/0-30647220-1_6

Ozdemir, A. S., Goktepe, S., \& Kepceoglu, I. (2012). Using Mathematics History to Strengthen Geometric Proof Skills. Procedia - Social and Behavioral Sciences, 46, 11771181. http://doi.org/10.1016/j.sbspro.2 012.05 .270

Panasuk, R. M., \& Bolinger Horton, L. (2013). Integrating History of Mathematics into the Classroom: Was Aristotle Wrong? Journal of Curriculum and Teaching, 2(2), 37-46. http://doi.org/10.5430/jct.v2n2p 37

Radford, L. (1997). On psychology, historical epistemology, and the teaching of mathematics: Towards a socio-cultural history of mathematics. For the 
ISSN 2089-8703 (Print) Vol. 6, No. 2 (2017)

ISSN 2442-5419 (Online)

Learning of Mathematics, 17, 26-33.

Radford, L. (2015). Of Love,

Frustration, and Mathematics: A

Cultural-Historical Approach to

Emotions in Mathematics

Teaching and Learning. In From

beliefs to dynamic affect systems

in mathematics education (pp.

25-49).

http://doi.org/10.1007/978-3-

319-06808-4_2

Radford, L., Bartolini Bussi, M. G., Bekken, O., Boero, P., Dorier, J.-L., Katz, V., ... Vasco, C. (2002). Historical formation and student understanding of mathematics (pp. 143-170). http://doi.org/10.1007/0-306-
47220-1_5

Tzanakis, C., Arcavi, A., de Sa, C. C., Isoda, M., Lit, C.-K., Niss, M., ... Siu, M.-K. (2002).

Integrating history of mathematics in the classroom: an analytic survey (pp. 201240). http://doi.org/10.1007/0306-47220-1_7

Tzanakis, C., Arcavi, A., de Sa, C. C., Isoda, M., Lit, C., Niss, M., ... Siu, M.-K. (2000). Integrating History of Mathematics in the Classroom: An Analytic Survey. History in Mathematics Education: The ICMI Study, 201-240.

http://doi.org/10.1007/0-30647220-1_7 